\title{
Floral Scent Emission from Nectaries in the Adaxial Side of the Innermost and Middle Petals in Chimonanthus praecox
}

\author{
Zhineng Li ${ }^{1,2,3,+}+\mathbb{D}$, Yingjie Jiang ${ }^{1,2,3,+}$, Daofeng Liu 1,2,3, Jing Ma ${ }^{1,2,3}$, Jing Li 1,2,3, \\ Mingyang Li ${ }^{1,2,3}$ and Shunzhao Sui ${ }^{1,2,3, *}$ \\ 1 College of Horticulture and Landscape Achitecture, Southwest University, Chongqing 400715, China; \\ znli@swu.edul.cn (Z.L.); sherneole@163.com (Y.J.); liu19830222@163.com (D.L.); \\ majing427@swu.edu.cn (J.M.); acejing@126.com (J.L.); limy@swu.edu.cn (M.L.) \\ 2 Key Laboratory of Horticulture Science for Southern Mountains Regions, Ministry of Education, \\ Chongqing 400715, China \\ 3 Chongqing Engineering Research Center for Floriculture, Chongqing 400715, China \\ * Correspondence: sszcq@swu.edu.cn; Tel.: +86-23-6825-0086 \\ + These authors contributed equally to this work.
}

Received: 10 September 2018; Accepted: 18 October 2018; Published: 22 October 2018

\begin{abstract}
Wintersweet (Chimonanthus praecox) is a well-known traditional fragrant plant and a winter-flowering deciduous shrub that originated in China. The five different developmental stages of wintersweet, namely, flower-bud period (FB), displayed petal stage (DP), open flower stage (OF), later blooming period (LB), and wilting period (WP) were studied using a scanning electron microscope (SEM) to determine the distribution characteristics of aroma-emitting nectaries. Results showed that the floral scent was probably emitted from nectaries distributed on the adaxial side of the innermost and middle petals, but almost none on the abaxial side. The nectaries in different developmental periods on the petals differ in numbers, sizes, and characteristics. Although the distribution of nectaries on different rounds of petals showed a diverse pattern at the same developmental periods, that of the nectaries on the same round of petals showed some of regularity. The nectary is concentrated on the adaxial side of the petals, especially in the region near the axis of the lower part of the petals. Based on transcriptional sequence and phylogenetic analysis, we report one nectary development related gene C $P C R C$ (CRABS CLAW), and the other four YABBY family genes, CpFIL (FILAMENTOUS FLOWER), CpYABBY2, CpYABBY5-1, and CpYABBY5-2 in C. praecox (accession no. MH718960-MH718964). Quantitative RT-PCR (qRT-PCR) results showed that the expression characteristics of these YABBY family genes were similar to those of 11 floral scent genes, namely, CpSAMT, CpDMAPP , CpIPP ,CpGPPS1, CpGPPS2, CpGPP, CpLIS, CpMYR1, CpFPPS, CpTER3, and CPTER5. The expression levels of these genes were generally higher in the lower part of the petals than in the upper halves in different rounds of petals, the highest being in the innermost petals, but the lowest in the outer petals. Relative expression level of CpFIL, CpCRC, CpYABBY5-1, and CpLIS in the innermost and middle petals in OF stages is significant higher than that of in outer petals, respectively. SEM and qRT-PCR results in C. praecox showed that floral scent emission is related to the distribution of nectaries.
\end{abstract}

Keywords: Chimonanthus praecox; nectary; floral scent; gene expression

\section{Introduction}

Nectaries are glandular structures that secrete nectar, a carbohydrate-rich solution that is composed mainly of sugars and it generally serves as a reward for pollinators or for as protectors (e.g., 
ants) against herbivores, or, as a lure for animal prey in carnivorous plants [1]. Nectaries are most wide spread in angiosperms, particularly within flowers, and in ferns and Gnetales [2]. Arabidopsis $C R C$ is expressed in the nectary throughout its development and plays a role in the specification and/or differentiation of the nectary [3]. CRC is also responsible for carpel growth and fusion, and floral meristem termination $[2,4,5]$. CRC encodes a putative transcription factor of the YABBY gene family, which also includes FIL, INO (INNER NO OUTER), YAB2 (YABBY2), YAB3, and YAB5 [6,7]. The YABBY family is characterized in Arabidopsis and rice [2,4,6,8-14]. INO expression occurs only in the abaxial domain of the ovule integument [4]. The "vegetative YABBYs" (FIL, YAB2, and YAB5) in angiosperm are exclusively expressed in leaf-homologous organs, both vegetative and floral, they are involved in leaf development, such as the leaf margin establishment that guides laminar growth and leaflet initiation; maintenance of leaf polarity; and, activation of leaf maturation processes and repression of shoot apical meristem genes [7]. Petunia $P h C R C 1 / 2$ expressed in developing nectaries and carpels, similar to Arabidopsis CRC expression [15,16]. No nectary glands develop in crc mutants [17]. Locations of nectaries are highly variable in broader taxonomic terms [18], although their locations within flowers are constant at the family level. Nectaries tend to be associated with the perianth in basal angiosperms [19], while they are usually associated with carpels and stamens in the eudicots. Fahn argued that nectaries position within flowers trends to shift from peripheral perianth positions in basal taxa to central positions that are associated with reproductive organs in more derived taxa [20].

Wintersweet (C. praecox) is a unique traditional deciduous woody flower that is popularly used in floral arrangement, bonsai growing, and landscaping in many countries because of its unique flowering time and distinctive fragrance in deep winter. Wintersweet is a potential spice material because of its volatile aromatic substances and can be used in perfumery, cosmetics, aromatic tea, aromatherapy, and the food industry [21-23].

More than 30 floral scent volatiles have been detected in C. praecox flowers, consisting almost exclusively of volatile benzenoids and terpenoids (monoterpenes and sesquiterpenes) [24,25]. Terpenoids play a leading role among these volatiles. These compounds in wintersweet have minimal molecular-genetic characterization, except for the homologous genes of CPFPPS and CPSAMT [22,26].

Here, we reported the distribution characteristics of nectaries in C. praecox and the expression profiles of nectary development related gene $C p C R C$, the other four $Y A B B Y$ family genes $(C P F I L$, $C p Y A B B Y 2, C p Y A B B Y 5-1$, and $C P Y A B B Y 5-2)$ and floral scent related genes to help understand floral scent origination and the molecular regulation of nectary development in wintersweet and other plants of scented flowers.

\section{Results}

\subsection{Distribution Characteristics of Nectary on Petals of Different Stages}

SEM analysis was performed to determine the distribution characteristics of nectary on petals in different stages of petals in different developmental stages of floral meristem (FB, DP, OF, LB, and WP), and receptacle, pistil, and stamen (Figure $1 \mathrm{~A}, \mathrm{~F}, \mathrm{~K}, \mathrm{R}, \mathrm{W}$ ). The nectaries were mainly located in the adaxial side of the innermost and middle petals (red asterisk shown, Figure 1B-E,G-J,L-O,S-V,X-Z2). The adaxial/abaxial side of the outer petals and the abaxial side of innermost/middle petals of different stages had no nectary distribution. Figure $1 \mathrm{P}, \mathrm{Q}$ show the adaxial and abaxial sides of the outer and middle petals in the OF stages (in green box), respectively, which there is no nectary detected at all. The numbers of nectaries changed in the FB to WP during flower senescence. The numbers of nectaries were equal or slightly higher in the middle petal than that in the innermost petal under the same magnification $(\times 400$, Figure 1). Morphological difference in different stages of nectaries are shown in Figure 1. With the development of floral meristem, the length-width ratio of nectaries became small and evaginated $(\times 1800$, Figure 1$)$. The substance of floral scent was found beside the nectaries (red arrow shown, Figure 1S,Z1,Z2). The cell size increased from FB and DP to OF with the development of floral meristem. This phenomenon is similar to that in LB and WP. Larger number of nectaries was 
observed in FB or DP than in OF at the same magnification $(\times 400)$ because of the different cell sizes in different development stages (Figure 1B,D,G,I,L,N). The number of nectaries in OF was higher than that in LB or WP (Figure 1L,N,S,U,X,Z1), with similar cell size in three different development stages.

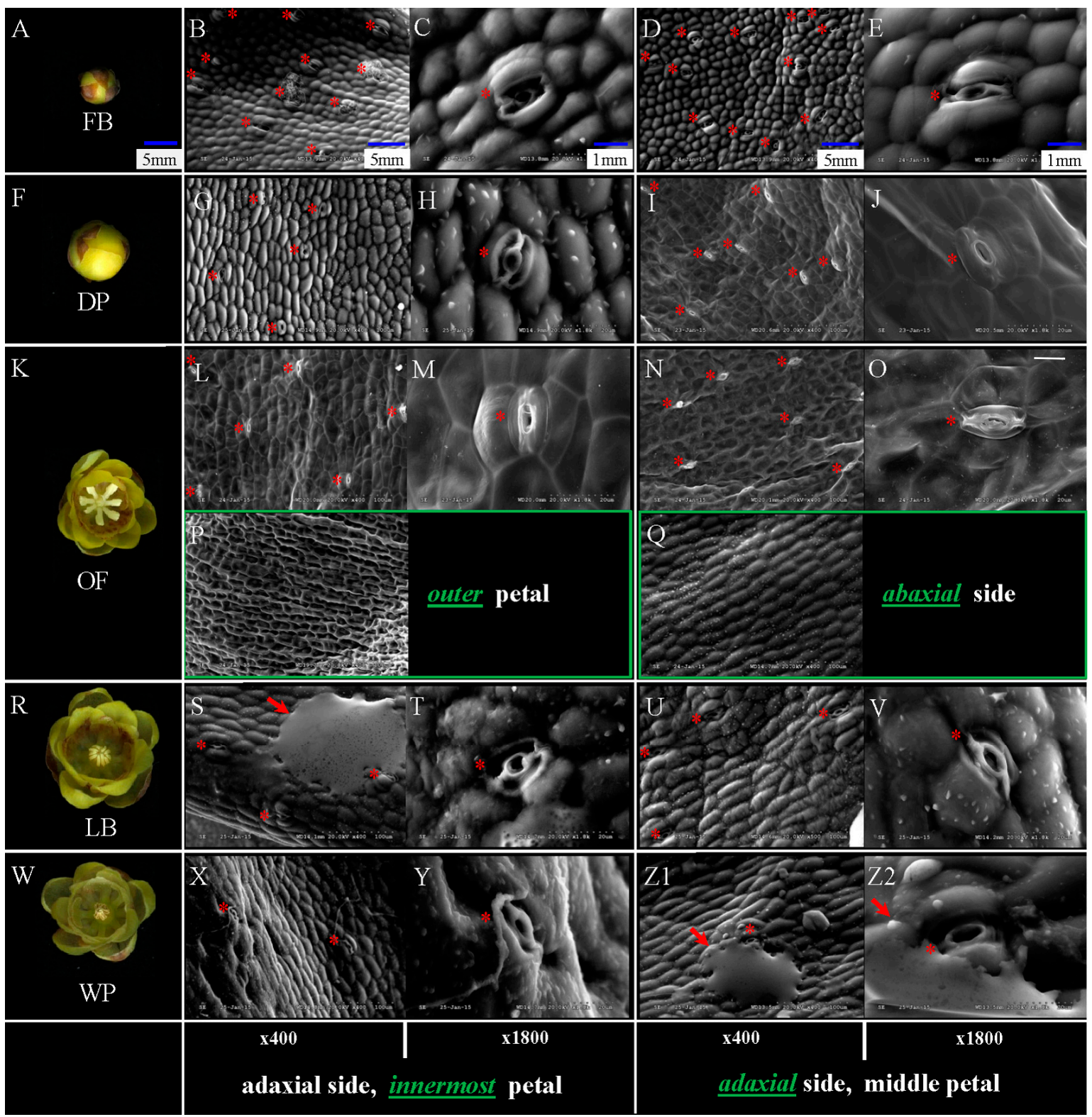

Figure 1. Morphology of the surface of petal glands on different stages in the Chimonanthus praecox by SEM. (A,F,K,R,W)floral meristem of five different developmental stages (FB, DP, OF, LB, and WP); $(\mathbf{B}, \mathbf{C} ; \mathbf{G}, \mathbf{H} ; \mathbf{L}, \mathbf{M} ; \mathbf{S}, \mathbf{T} ; \mathbf{X}, \mathbf{Y})$ nectaries on adaxial side of innermost petals in five different developmental stages. (D,E;I,J;N, $\mathbf{O} ; \mathbf{U}, \mathbf{V} ; \mathbf{Z 1}, \mathbf{Z 2})$ nectaries on the adaxial side of middle petals in five different developmental stages. (B,D,G,I,L,N,S,U,X,Z1) surface of the glandular tissue, showing the nectary stomata (red asterisk). (C,E, $\mathbf{H}, \mathbf{J}, \mathbf{M}, \mathbf{O}, \mathbf{T}, \mathbf{V}, \mathbf{Y}, \mathbf{Z 2})$ close-up of the nectary stomata. (P,Q) (in green box) no nectary distribution on adaxial side of outer petal and abaxial side of middle petals in $O F$ stages. Scale bar is the same in $(\mathbf{A}, \mathbf{F}, \mathbf{K}, \mathbf{R}, \mathbf{W}) ;(\mathbf{B}, \mathbf{D}, \mathbf{G}, \mathbf{I}, \mathbf{L}, \mathbf{N}, \mathbf{P}, \mathbf{Q}, \mathbf{S}, \mathbf{U}, \mathbf{X}, \mathbf{Z 1})$; and $(\mathbf{C}, \mathbf{E}, \mathbf{H}, \mathbf{J}, \mathbf{M}, \mathbf{O}, \mathbf{T}, \mathbf{V}, \mathbf{Y}, \mathbf{Z 2})$, respectively. Red arrow shows the substance of floral scent. The magnification was $\times 400$ (left) and $\times 1800$ (right), respectively.

No nectary was detected on the receptacle, perianth, stamen, and pistilin all five stages (FB, $\mathrm{DP}, \mathrm{OF}, \mathrm{LB}$, and WP) (just show results in OF stage, Figure 2). Concentrated nectaries were found in the region near the axis of the lower part of petals, but almost none in the upper and edge of 
petals (Figure 3 just show the stages of $\mathrm{FB}$ and $\mathrm{OF}$ ). Nectaries are not uniformly distributed in the petals (Figures 1B,D,G,I,L,N,S,U,X,Z1 and 3). These distribution characteristics of nectaries were perhaps related to the $Y A B B Y$ gene family, which controls the build of nectaries development and dorsiventral polarity.

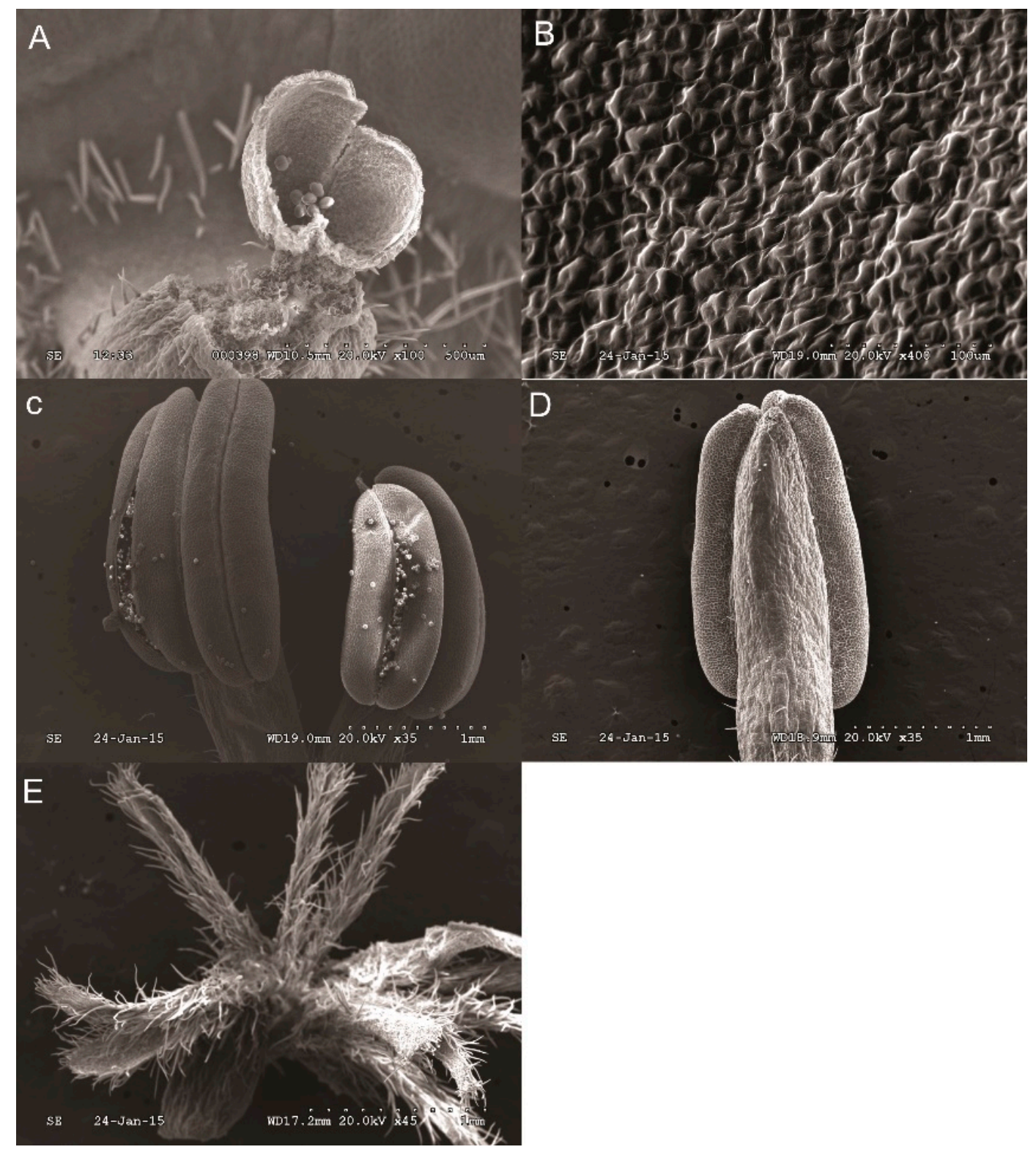

Figure 2. No nectaries distribution of the stamen and pistil in OF in the Chimonanthus praecox by SEM. (A), receptacle; (B), perianth; (C), front of stamen; (D), back of stamen; and, (E), pistil. 


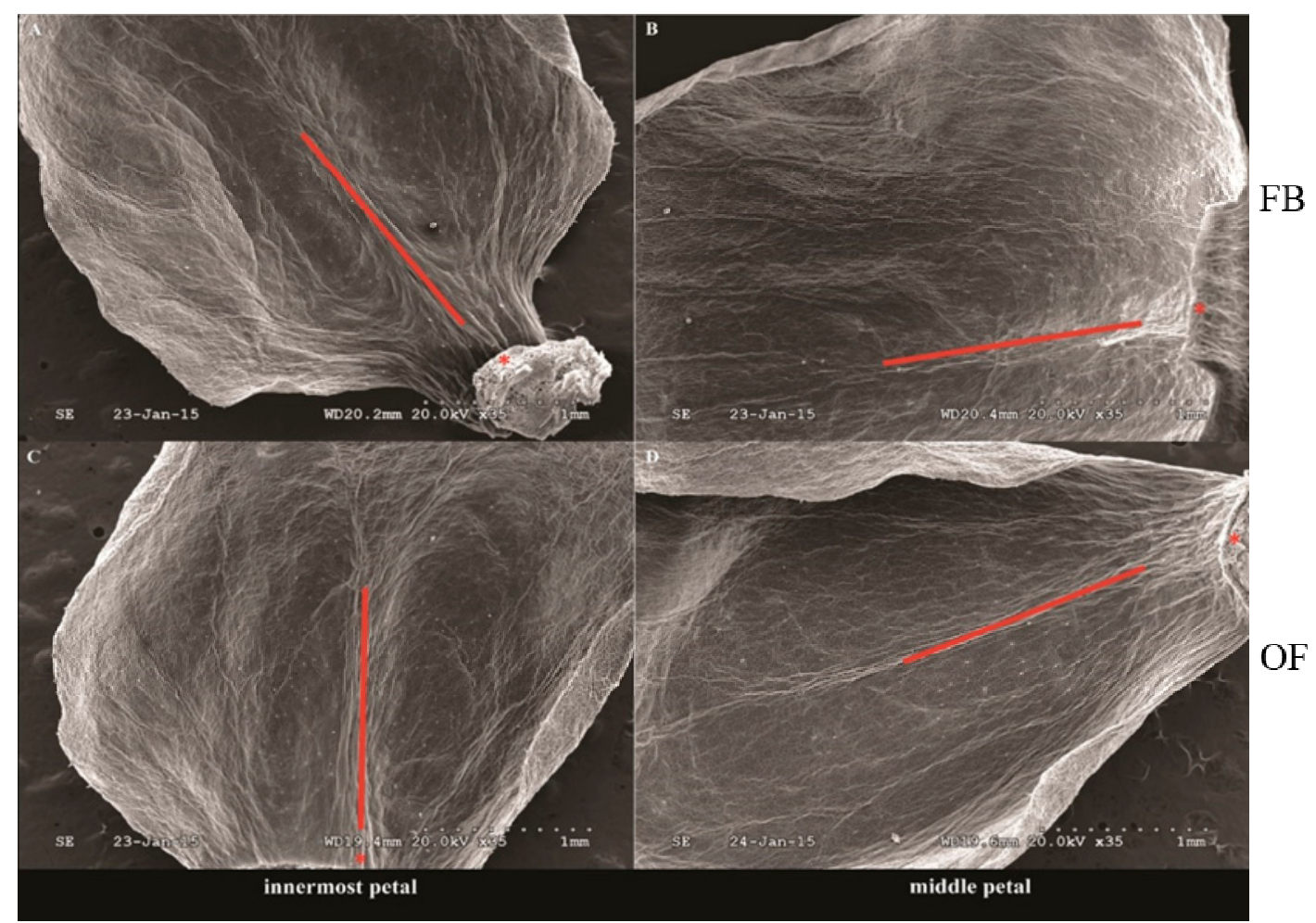

Figure 3. Distribution of the nectaries in FB and OF in the Chimonanthus praecox by SEM. Little white dot shown the nectaries concentrated near the axis of petals. Red line represented the axis of the petal. Red asterisks show the bottom of the petal.

\subsection{Sequence Alignment and Phylogenetic Analysis}

Partial or complete CpFIL, CpCRC, CPYABBY2, CpYABBY5-1, and CpYABBY5-2 cDNAs contain open reading frame of $636,519,546,555$, and 552bp, respectively. The predicted CpFIL, CPCRC, CPYABBY2, CpYABBY5-1, and CPYABBY5-2 proteins of 212, 173, 182, 185, and 184 amino acid residues contains a zinc-finger domain in the N-terminus and a YABBY domain in the C-terminus (Figure 3A). The putative CpFIL protein shares $89 \%$ and $82 \%$ similarity with MgFIL from Magnolia grandiflora and Ny.coFIL from Nymphaea colorata. CpCRC protein shows $67 \%$ and $59 \%$ identity with the products of NnCRC-1/2 in Nelumbo nucifera and AtCRC in Arabidopsis. CpYABBY2 protein shares $72 \%$ and 57\% similarity with NnYAB2 from N. nucifera and AtYAB2 from Arabidopsis, respectively. The putative CpYABBY5-1 protein shared high similarity (81\%) with CpYABBY5-2, and they both showed 89\% and $93 \%$ identity with the products of CsYAB5 in Chloranthus serratus, and $72 \%$ and $69 \%$ with that of AtYABBY5 in Arabidopsis (Figure 4A and Figure S1; Table S1).

The sequences of the five YABBYs protein homologues were aligned with the respective FIL, CRC, YABBY2, YABBY5-1, and YABBY5-2 proteins of the multiple angiosperm taxa for phylogenetic analysis. The CpYAB2 homologue clustered with non-core NnYAB2 of Nelumbo nucifera, D1YAB2 of Dimocarpus longan, Am.trYAB2 from Amborella trichopoda and core AtYAB2 from A. thaliana. The two YABBY5 sequences from $C$. praecox, CpYAB5-1 and CpYAB5-2, formed a sister group to the basal eudicot, CsYAB5 of Chloranthus serratus, formed a clade YABBY5 with AtYAB5 of $A$. thaliana. The CpFIL sequence aligned near to none-core basal eudicots, MgFIL of Magnolia grandiflora, NjFIL of Nuphar japonica, Nymphaea colorata Ny.coFIL and A. trichopoda Am.trFIL, and formed FIL clade. Together with A. thaliana AtCRC, the CpCRC, A. trichopoda Am.trCRC, Oryza sativa OsCRC, EsCRC of Epimedium sagittatum, EcCRC of Eschscholzia californica, N. nucifera NnCRC-1, and NnCRC-2 formed a clade of CRC (Figure 4B). 


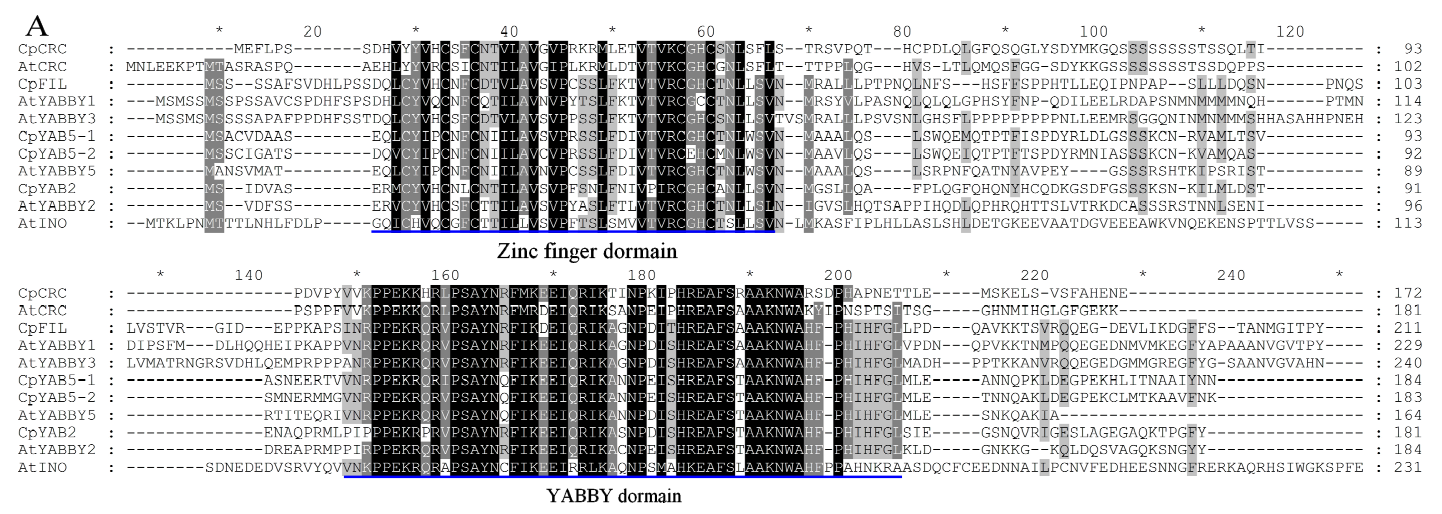

B

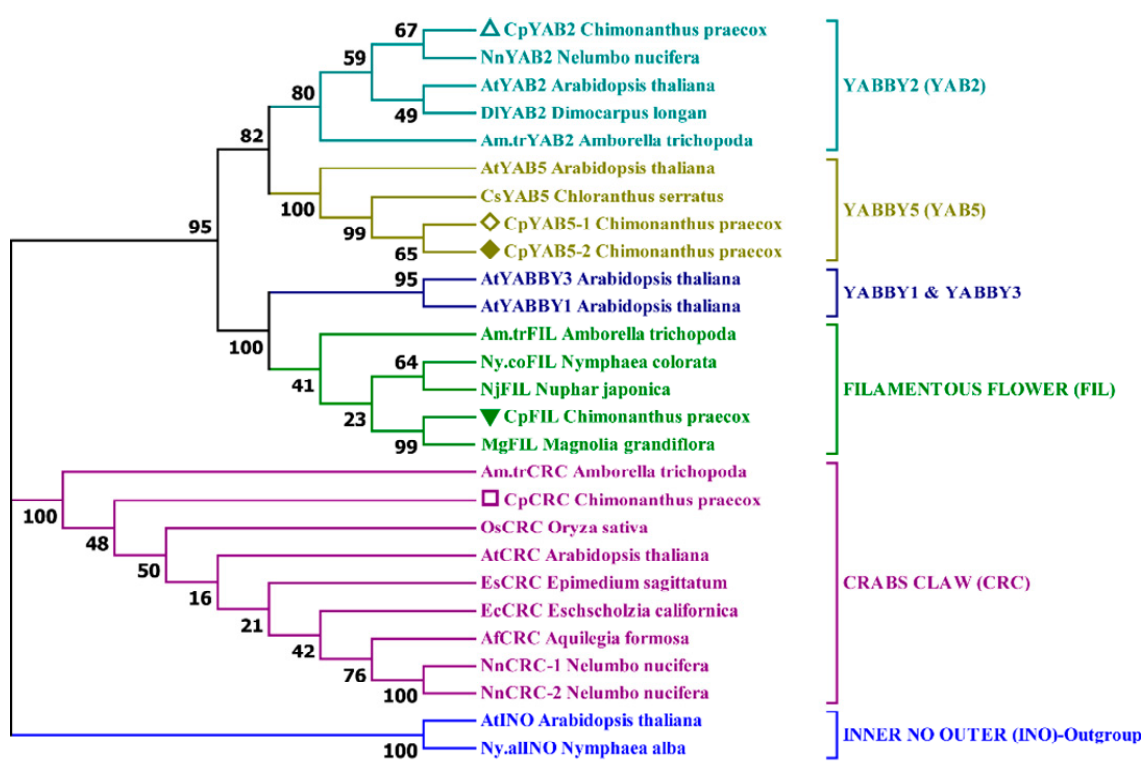

Figure 4. Sequence alignment and phylogenetic analysis of YABBY proteins. (A) Sequence alignment of YABBY proteins in C. praecox and A. thaliana. Conserved domains (Zinc finger domain and YABBY domain) are underlined in blue. Identical residues are highlighted in black and similar residues are highlighted in grey. Dotted line and asterisk represented the gap and the position of odd times of ten in protein sequence. (B) Phylogenetic analysis by Neighbor-joining (NJ) bootstrap analysis (1000 replications). AtINO (A. thaliana) and Ny.alINO (Nymphaea alba) as outgroup. The gene accession number is shown in Materials and Methods. Five different symbols in front of the protein name reprent the five YABBY protein of Chimonanthus praecox in this study.

\subsection{Expression Analysis}

In order to illustrate the correlation between nectary development and gene expression of $C p C R C$ and the other four YABBY genes, also that of the nectary development and the floral scent, heatmap analysis with the RNA-Seq database in DP, OF, and WP stages [27] and qRT-PCR were conducted using cDNA derived from DP, OF, LB, and WP to determine the expression profile of five YABBY genes and 11 floral scent related genes in the flower buds of different developmental stages in C. praecox (Figure $1 \mathrm{~F}, \mathrm{~K}, \mathrm{R}, \mathrm{W}$ ). Almost no CpDMAPP was detected in DP, OF, LB, and WP. The relative expression of one nectary development related gene $C p C R C$ and the other four YABBY family genes (CPFIL, C $Y$ YABBY 2, CpYABBY 5-1, and CpYABBY 5-2) and seven floral scent genes (CpSAMT, CpIPP, Cp GPPS1, CpGPP, CpLIS, CPTER3, and CPTER5) gradually increased in OF to LB and WP. The expression levels of CPFIL, CPCRC, CPYABBYY2, CPYABBY 5-2, and CPTER3 were the highest, and those of CpGPPS1 and CpTER5 were the lowest in DP. The expression of CPYABBY5-1, CpSAMT, CPIPP, CpGPP, and CpLIS in DP was higher than that in OF but lower than that in WP. The highest and lowest expression levels of 
CpGPPS2 and CPMYR1 were in LB and OF, respectively. The expression of CpFPPS in DP was similar to that in LB, higher than that in OF, and lowest in WP (Figure 5).

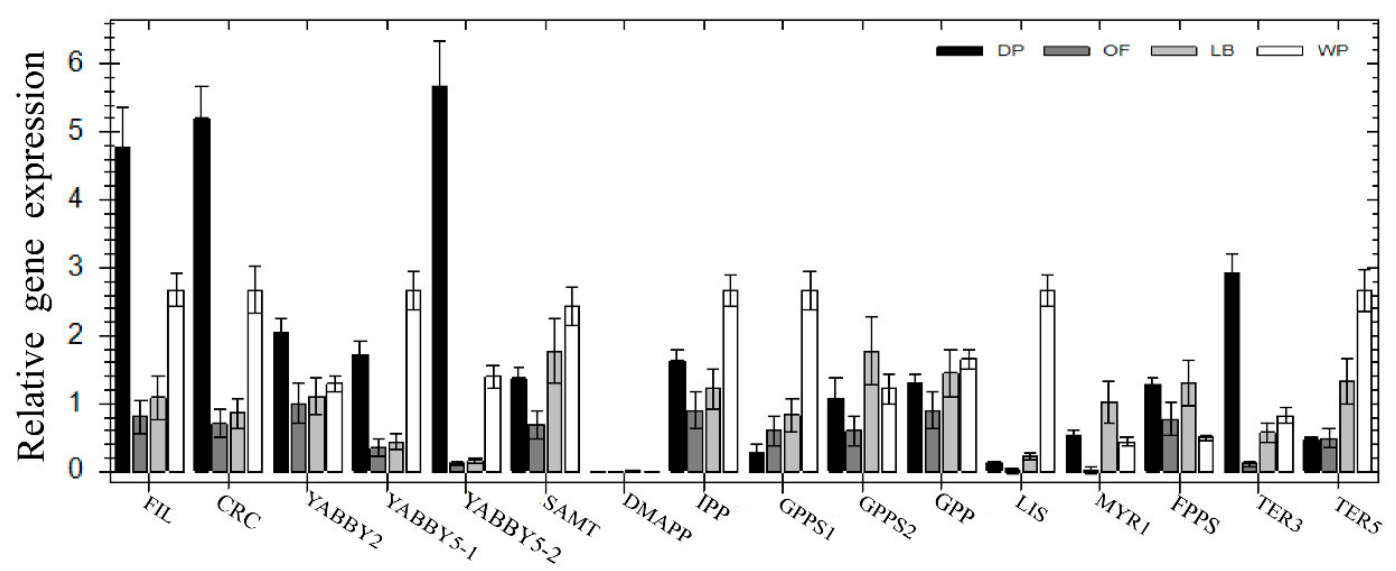

Figure 5. Quantitative real-time PCR analysis of different genes in four different developmental stages of DP, OF, LB, and WP. Tublin homologous gene of Chimonanthus praecox was used as an internal control.

According to the RNA-Seq database in DP, OF and WP stages, CpFIL, CpCRC, CpYABBYY, CPYABBY5-1, and CPYABBY5-2 have similar expression pattern. The expression level in DP was higher than that in OF and WP and the lowest in WP (Figure 6).
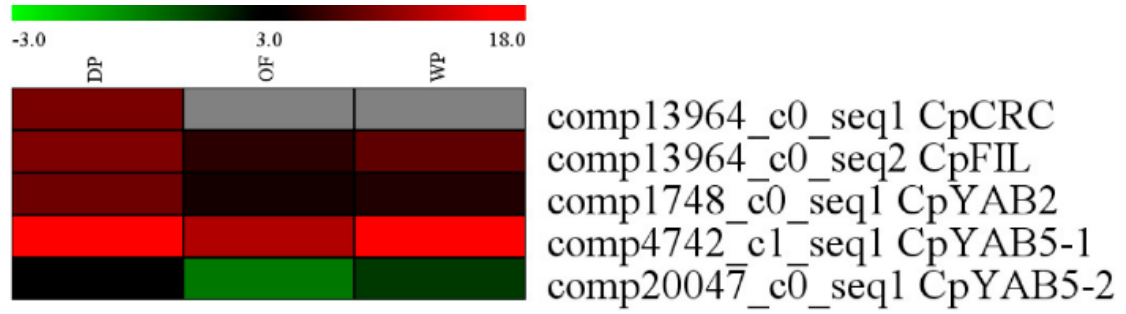

Figure 6. Heatmap analysis of 5 YABBY family gene expression in DP, OF, and WP stages.

To further clarify the correlation between the distribution characteristics of nectaries in three different round of petals and gene expression, the expression profile of five YABBY genes and five floral scent related genes in the innermost, middle, and outer petals in OF stages (Figure 1K) was detected using qRT-PCR. The expression level of 5 YABBY genes and five floral scent-related genes gradually decreased in the innermost to the middle and outer petals. The relative expression levels of CpFIL, CpCRC, CPYABBY2, CpYABBY5-1, and CPYABBY5-2 in the innermost petals were 1.78- to 5.38-fold, and 3.24- to 12.57-fold higher than that in the middle and the outer petals, respectively. The relative expression levels of floral scent genes (CPIPP, CPGPPS1, CpGPP, CpLIS, and CpTER5) in the innermost petals were approximately 1.65- to 10.25-fold higher than those in the middle petals and 1.76- to 78.85-fold higher than those in the outer petals (Figure 7). They all have significant difference between the relative expression level of C $P F I L, C p C R C, C p Y A B B Y 5-1$, and C $p L I S$ in middle petals and that of in outer petals (Figure 7).

Based on SEM results, for the sake of the relationship between the distridution characteristics of nectaries in the same round of petals and the gene expression, qRT-PCR was conducted using cDNA derived from the upper and lower halves in middle petals from DP, OF, and WP (Figure 1F,K,W) to further detect the expression profile of one nectary development related gene $C p C R C$, four YABBY family genes (CpFIL, CPYABBY2, CpYABBY 5-1/2) and two floral scent genes (CpIPP and CpGPPS1). The relative expression of these five YABBY family genes and C $P I P P$ had a similar expression pattern. The expression levels in the lower half of middle petals were higher than those in the upper halves in DP and OF stages, including the CPYABBY5-1 and CPYABBY 5-2 in the WP stage and CpGPPS1 in the 
DP stage. However, the relative expression levels of CpFIL, CpCRC,CpYABBY2, CpIPP, and CpGPPS1 in the lower half of middle petals were lower than those in the upper halves in WP stage and were similar to those of CPGPPS1 in the OF stage (Figure 8).

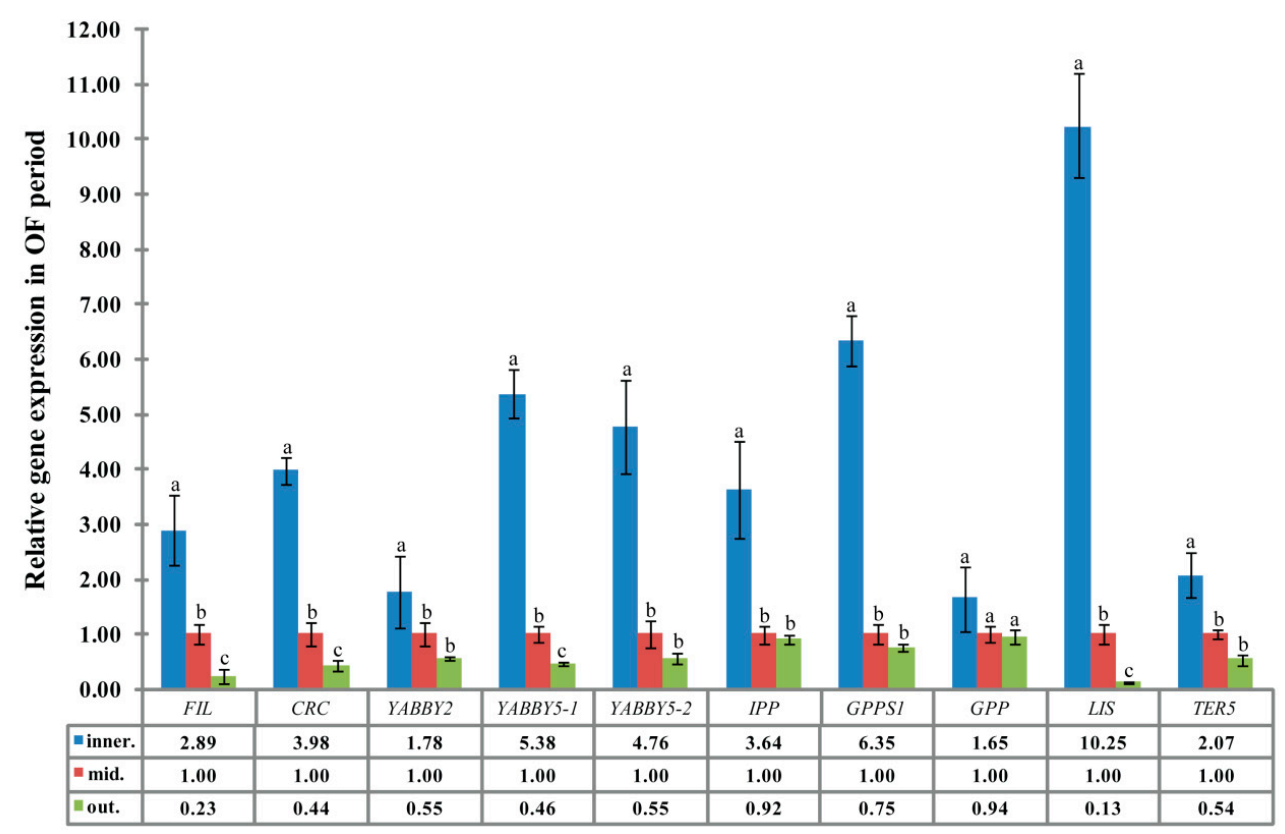

Figure 7. Quantitative real-time PCR analysis of different genes in three different rounds of petals in OF stages. Inner., mid., and out. represent innermost, middle, and outer petals, respectively. Tublin homologous gene of $C$. praecox was used as aninternal control. (Notes: $t$-test used for significant difference analysis; data is the means of relative expression; $a, b, c$ show $p<0.05$ significant level).

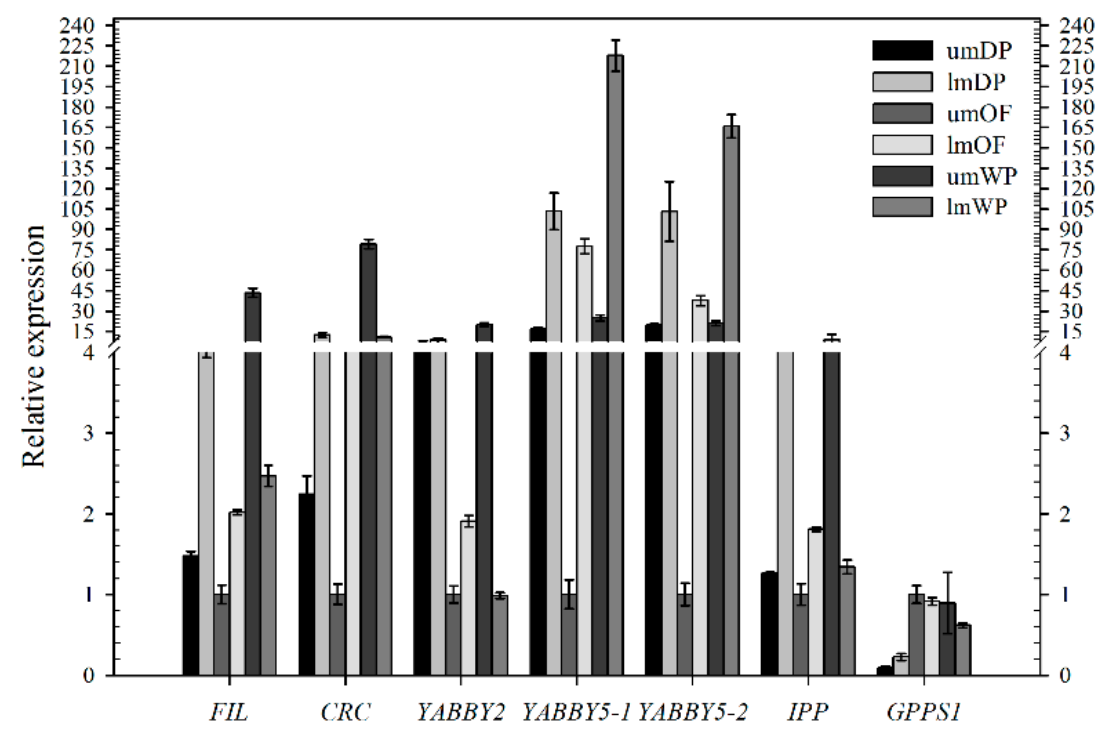

Figure 8. Quantitative real-time PCR analysis of different genes in the upper and lower halves of middle petals in DP, OF, and WP stages. Tublin homologous gene of C. praecox was used as an internal control. "um" and "lm" represent upper and lower half of middle petals, respectively.

\section{Discussion}

Results of SEM analysis in C. praecox show that nectaries were distributed on the adaxial side of the innermost and middle petals but not on the abaxial side. No nectary was detected in all five stages (FB, DP, OF, LB, and WP) on the outer petals, including in the receptacle, perianth, stamen, and pistil. The surface morphology of the innermost and middle glands of $C$. praecox is similar to that of 
the inner petal glands of Alphonsea glandulosa and Petunia $[16,28]$. The surface of the nectar glands is different from the surrounding epidermis, and nectar stomata are found across the surface of the glandular tissues [28]. The nectar stomata are raised slightly above the epidermis with an aperture for nectar secretion [29]. Although the locations of nectaries within flowers vary highly in terms of broader taxonomic terms, their locations are constant at the family level [30]. Nectaries are usually associated with carpels and stamens in eudicots, but are related to perianth in basal angiosperms [19]. C. praecox belongs to Calycanthaceae, Laurales, Magnoliids, and is clustered to Magnoliales, Piperales, and Canellales, which are close to Chloranthales, Austrobaileyales, Nymphaeales, and Amborellales [31]. In Magnoliidae, C. praecox has no nectary distribution on its receptacle, perianth, stamen, or pistil, but has some on the adaxial side of the innermost and middle petals; this finding partly supports that of a previous study, nectaries position within flowers trends to shift from peripheral perianth in basal taxa to central reproductive organs in more derived taxa $[19,20]$.

Monoterpenes, such as myrcene, geraniol, linalool and sesquiterpene compounds, are the main aroma components of C. praecox [32,33]. Therefore, the concentration of universal precursor of monoterpene (GPP) and its substrate IPP can indirectly reflect the aroma production of C. praecox. qPCR analysis of CPIPP and C $P$ GPPS gene in different parts of petals can indirectly determine the location of aroma substances. The expression levels of the nectary development related genes $C p C R C$, the other four YABBY family genes (CPFIL, CPYABBY2, and CPYABBY5-1/2) and five floral scent genes (CPIPP, Cp GPPS1, CpGPP, CpLIS, and CPTER5) in the innermost petals of C. praecox were higher than those in the middle and outer petals, but they were the lowest in the outer petals. The CPLIS expression was increased seven-fold at the OF stage, which is responsible for $\alpha$-linalool biosynthesis [27]; and $\alpha$-linalool accounts for $36 \%$ of the total quantity of volatile compounds has been reported in wintersweet flowers [34]. The expression results were consistent with the characteristics of nectary distribution based on SEM analysis (Figures 1 and 7).

The expression pattern of five YABBY genes in C. praecox by qPCR was in accordance with the RNA-Seq in DP, OF, and WP stages (Figures 5 and 6). The expression levels of CPIPP and CpGPPS were significantly different in the different halves of the petals; those in the upper halves were significantly lower than those in the lower halves during the first two periods. This result is consistent with that of SEM analysis (Figure 1), which stated that the nectaries were mainly distributed in the lower half part of the petals near the axis and were rarely distributed on the edge and upper half part of the petals. Nectaries are not uniformly distributed in the petals, that is why the numbers of nectaries were equal or slightly higher in the middle petal than that in the innermost $(\times 400$, Figure 1$)$. The expression characteristics of $C p F I L, C p C R C, C p Y A B B Y 2$, and $C p Y A B B Y 5-1 / 2$ were generally similar to those of CPIPP and CPGPPS.

At least one YABBY gene family member $C p C R C$ was expressed in all asymmetric above-ground organs in a polarity, suggesting that this gene is involved in establishing dorsiventral polarity in all of these organs. The YABBY gene family controls the build of dorsiventral (abaxial/adaxial) polarity $[4,10,35]$. Therefore, we proposed that the floral scent mainly originates from the nectaries that are distributed neither on the abaxial side of the innermost and middle petals nor on the outer petals, but on the adaxial side of the innermost and middle petals. This unbalanced distribution of the nectaries is caused by dorsiventrality differentiation, one of the most important polarities in the development of lateral organs in plants.

\section{Materials and Methods}

\subsection{Plant Material}

C. praecox plants of 21-years old were grown in the campus of Southwestern University $\left(106^{\circ} 43^{\prime} \mathrm{E}\right.$, $29^{\circ} 83^{\prime} \mathrm{N}$, Beibei District, Chongqing City, China) under natural photoperiod. Flower development was divided into the following five stages: FB is the stage wherein the flower bud is closed, and the petals are yellow; DP wherein the petals unroll; OF wherein the petals reach full opening, and the 
stamens bent toward the adaxial side of innermost petals and away from the pistils at a right angle; LB that occurs after two days of OF, where the stamens commence to move to enclose the pistils; and WP wherein the flower is pollinated, and the petals and stamens start to wilt. Floral tissue samples, such as receptacle, sepals, petals, stamens, and pistils were obtained from five different stages. Some of the petals were divided into upper and lower halves. All plant materials were harvested then fixed with FAA buffer or frozen in liquid nitrogen and stored at $-80^{\circ} \mathrm{C}$ for RNA extraction.

\subsection{Scanning Electron Microscope (SEM)}

Fresh petals of $C$. praecox were soaked for an hour in pre-cold $2 \%$ glutaraldehyde solution and then were rinsed three to four times with $0.1 \mathrm{M}$ phosphate buffer ( $\mathrm{pH}$ 7.2) for $1 \mathrm{~h}$. The buffer was discarded, and ethanol dehydration was conducted in a step-by-step gradient. Ethanol concentrations were $30 \%, 50 \%, 70 \%, 80 \%, 90 \%$, and $100 \%$ for 25 min each. The alcohol was washed, and $1: 1$ mixture of isoamyl acetate to ethanol was added. Then, the solution was added with pure isoamyl acetate, soaked for 10-20 min for each step, stirred properly, and air dried before the electron microscope observation.

\subsection{Sequence Alignment and Phylogenetic Analysis}

The sequences of one nectary development related gene $C R C$, four other YABBY family genes (FIL, YABBY2, YABBY5-1/2) and 11 floral scent genes in C. praecox were selected from the Illumina deep sequencing [27]. Blastn of these genes were obtained and named as CpFIL, CpCRC, CPYABBY2, CpYABBY 5-1, CpYABBY 5-2, CpSAMT, CpDMAPP, CPIPP, Cp GPPS1, Cp GPPS2, Cp GPP, CPLIS, CPMYR1, CPFPPS, CPTER3, and CPTER5. The sequences included in the analysis were downloaded from the NCBI GenBank (http:/ / www.ncbi.nlm.nih.gov). The amino acid sequences of the YABBY family were aligned using ClustalX 1.83 [36]. Neighbor-joining (NJ) bootstrap analysis (1000 replications) with Poisson correction for the amino acids was performed using MEGA 4 [37]. Sequence data for analysis can be found in the GenBank/EMBL databases under the following accession numbers: $C p F I L, C p C R C, C p Y A B B Y 2, C p Y A B B Y 5-1$ and $C p Y A B B Y 5-2$ from $C$. praecox; AtINO, AtCRC, AtYABBY1, AtYABBY2, AtYABBY3, and AtYABBY5 (AAF23754, NP_177078, NP_566037, AF136539, AF136540, NM_179749) from A. thaliana; Am.trCRC, Am.trFIL, and Am.trYAB2 (AJ877257, AB168113, AB126654) from Amborella trichopoda; AfCRC (AY854797) from Aquilegia formosa; CsYAB5 (BAF65259) from Chloranthus serratus; DlYAB2 (ACN59438) from Dimocarpus longan; EsCRC (GH62810) from Epimedium sagittatum; EcCRC (CAQ17052) from Eschscholzia californica; NnYAB2, NnCRC-1, and NnCRC-2 (XP_010247861, XM_010259669, XM_010259670) from Nelumbo nucifera; NjFIL (BAD83708) from Nuphar japonica; Ny.alINO (AB092980) from Nymphaea alba; Ny.coFIL (BAF65258) from Nymphaea colorata; MgFIL (BAF65261) from Magnolia grandiflora; and OsCRC (AAR84663) from Oryza sativa.

\subsection{Gene Expression Analysis}

Tissues sampled for gene expression analysis include flower buds of four different developmental stages (DP, OF, LB, and WP), three different rounds (innermost, middle, and outer) of petals in OF stages, the upper and lower halves of middle petals in DP, OF, and WP stages. Total RNA for the expression analysis was extracted using RNAprep pure kit (Tiangen, Beijing, China) according to the manufacturer's instructions. Exactly $3 \mu \mathrm{g}$ of RQ1 RNase-Free DNase (Promega, Madison, WI, USA) pre-treated total RNA was reverse transcribed according to the instructions of the Primescript RT reagent kit (Takara, Tokyo, Japan). qRT-PCR was performed to determine the expression pattern of one nectary development related gene $C p C R C$, four YABBY family genes (CpFIL, Cp YABBY2, C $P$ YABB Y 5-1, and CPYABBY5-2) and 11 floral scent genes, such as CPSAMT, CpDMAPP, CPIPP, Cp GPPS1, CpGPPS2, CPGPP, CPLIS, CPMYR1, CPFPPS, CPTER3, and CPTER5.

The primers for qRT-PCR are listed in Table 1. Reactions were performed with the Sso Fast Eva Green Supermix (Bio-Rad, Hercules, CA, USA) and analyzed using Bio-Rad CFX96 (Bio-Rad CFX Manager Software Version 1.6). Thermocycler conditions were $95^{\circ} \mathrm{C}$ for $30 \mathrm{~s}$, followed by 40 cycles of 
$95{ }^{\circ} \mathrm{C}$ for $5 \mathrm{~s}$ and $60^{\circ} \mathrm{C}$ for $5 \mathrm{~s}$. qRT-PCR products were amplified using $5 \mu \mathrm{L} 2 \times$ Sso Fast Eva Green Supermix, $0.5 \mu \mathrm{L}$ RT reaction mixture, $0.5 \mu \mathrm{L}$ of forward and reverse primer $(10 \mu \mathrm{mol} / \mu \mathrm{L})$ each, and RNase Free $\mathrm{dH}_{2} \mathrm{O}$ to a final volume of $10 \mu \mathrm{L}$. Relative amounts of transcripts were calculated using the comparative CT method $\left(2^{-\Delta \Delta C t}\right)$, and the values were normalized. The house-keeping gene CpTublin of C. praecox was used as internal control. Data are shown as mean values \pm standard deviation (SD) from three replicates for each sample. Significant difference was carried out by $t$-test $(p<0.05)$.

The expression patterns of the five YABBY genes were estimated by FPKM values and were visualized using MultiExperiment Viewer (Broad Institute of MIT and Harvard University, Boston, MA, USA [38]).

Table 1. Primer for real-time PCR.

\begin{tabular}{|c|c|c|}
\hline Gene Name & Forward Primer Sequence & Reverse Primer Sequence \\
\hline Actin & AGGCTAAGATTCAAGACAAGG & TTGGTCGCAGCTGATTGCTG \\
\hline CpFIL & AATCCCGACATAACCCACAGAGAG & TCCTGTTGGCGCACGCTAGTT \\
\hline$C p C R C$ & ССТСССGТСАССТТАСАААСТАСАG & CTGCTACAAGGAACACTGACCGC \\
\hline CP ҮABBY2 & CCATTGTCAAGATAAAGGTAGCGATT & CTGGTGGTGGTATAGGTAGCATTCG \\
\hline СР ҮАВВҮ5-1 & ТСТСССТСТСТАTTTATCСТCGTTT & GTAAAAGGCTAAAGCAGGATCATG \\
\hline CPYABВҮ5-2 & TTTTGAACACTGGAAACTTCGTCTT & GATGCAGCTCGACATCTCACTATCT \\
\hline SAMT & ACCATTTTCACATCATTGCCAGAC & СТTССТСТTTTAССАTСAAGTGCTG \\
\hline$D M A P P$ & ATCGGAGAAGAAAGTGAGCGAGAGT & GCCGTGTATCGAAGCAGCAGT \\
\hline$I P P$ & CAGACCATCTCTTTCTCССАСТTTC & GGTCGGAGAGAAGGTGGTAGAGGTA \\
\hline GPPS1 & GTTAGCCAАСТTTCCАТАССАТTTC & GAGTGACAACATCATCAAAGAAGGG \\
\hline GPPS2 & ATGAAGATGATTAGATTTCGAGTCCAAG & ATAACCAATTTACAACСССТGACCC \\
\hline$G P P$ & TCTACAGAAAATGGGAGAAAACGAT & TATCTGTTTCTGTCACCAAATCCAC \\
\hline LIS & GGCCAAAGTTAATGAAGTGAGATCC & CGTATATGCCATCGTTGCTGCC \\
\hline MYR1 & TTTCACAAAAATTGCCTTCAACCTT & CAAGGTGATGGAGAACTAAAACAAAAC \\
\hline FPPS & TCTTTGTCCAGTTCTTCCAGCGTT & ATCAGTGAAATCAAAGGCGGAATCT \\
\hline TER3 & AGAGTTGAATTGCACAGGGTGATAG & GCAGTGGATGTTGTTGATCAGCTC \\
\hline TER5 & СТСТСССТСАGТСТСТТСТСССТTТ & ATCTCCATGCAACATTGGCTACAG \\
\hline
\end{tabular}

Supplementary Materials: Supplementary materials can be found at http:/ / www.mdpi.com/1422-0067/19/10/ 3278/s1.

Author Contributions: Methodology, Z.L. and Y.J.; Software, Z.L.; Validation, Z.L. and J.L.; Formal Analysis, Y.J. and Z.L.; Resources, D.L.; Data Curation, J.M.; Writing-Original Draft Preparation, Y.J. and Z.L.; Writing-Review \& Editing, Z.L.; Visualization, Z.L. and Y.J.; Supervision, Z.L.; Project Administration, S.S. and M.L.; Funding Acquisition, Z.L., S.S. and J.M.

Funding: This work was supported by grants from Fundamental Research Funds for the Central Universities (XDJK2017B031), the National Natural Science Foundation of China (No. 31500573, 31370698), Chongqing science and technology committee projects (cstc2016shmszx80112), Chongqing education committee projects (yjg20163042) and National undergraduate innovation and entrepreneurship training program (201410635065).

Conflicts of Interest: The authors declare no conflict of interest.

$\begin{array}{ll}\text { Abbreviations } \\ \text { SEM } & \text { scanning electron microscope } \\ \text { qRT-PCR } & \text { quantitative Reverse Transcript-Polymerase Chain Reaction } \\ C R C & \text { CRABS CLAW } \\ \text { FIL } & \text { FILAMENTOUS FLOWER } \\ \text { INO } & \text { INNER NO OUTER } \\ \text { YAB } & \text { YABBY } \\ \text { SAMT } & \text { S-adenosyl- } L \text {-methionine: salicylic acid carboxyl methyltransferase } \\ \text { DMAPP } & \text { dimethylallyl pyrophosphate } \\ \text { IPP } & \text { isopentenyl pyrophosphate } \\ \text { GPPS } & \text { geranyl diphosphate synthase } \\ \text { GPP } & \text { geranyl pyrophosphate } \\ \text { LIS } & \text { S-linalool synthase } \\ \text { MYR1 } & \text { myrcenesynthase } \\ \text { FPPS } & \text { farnesyl pyrophosphonate synthase } \\ \text { TER } & \alpha \text {-terpineol synthase }\end{array}$




\section{References}

1. Schmid, R. Reproductive versus extra-reproductive nectaries-historical perspective and terminological recommendations. Bot. Rev. 1988, 54, 179-227. [CrossRef]

2. Lee, J.Y.; Baum, S.F.; Alvarez, J.; Patel, A.; Chitwood, D.H.; Bowman, J.L. Activation of CRABS CLAW in the Nectaries and Carpels of Arabidopsis. Plant Cell 2005, 17, 25-36. [CrossRef] [PubMed]

3. Baum, S.F.; Eshed, Y.; Bowman, J.L. The Arabidopsis nectary is an ABC-independent floral structure. Development 2001, 128, 4657-4667. [PubMed]

4. Bowman, J.L. The YABBY gene family and abaxial cell fate. Curr. Opin. Plant Biol. 2000, 3, 17-22. [CrossRef]

5. Gross, T.; Broholm, S.; Becker, A. CRABS CLAW Acts as a Bifunctional Transcription Factor in Flower Development. Front. Plant Sci. 2018, 9, 835. [CrossRef] [PubMed]

6. Goldshmidt, A.; Alvarez, J.P.; Bowman, J.L.; Eshed, Y. Signals derived from YABBY gene activities in organ primordia regulate growth and partitioning of Arabidopsis shoot apical meristems. Plant Cell 2008, 20, 1217-1230. [CrossRef] [PubMed]

7. Bartholmes, C.; Hidalgo, O.; Gleissberg, S. Evolution of the $Y A B B Y$ gene family with emphasis on the basal eudicot Eschscholzia californica (Papaveraceae). Plant Biol. 2012, 14, 11-23. [CrossRef] [PubMed]

8. Siegfried, K.R.; Eshed, Y.; Baum, S.F.; Otsuga, D.; Drews, G.N.; Bowman, J.L. Members of the YABBY gene family specify abaxial cell fate in Arabidopsis. Development 1999, 126, 4117-4128. [PubMed]

9. Eshed, Y.; Baum, S.F.; Bowman, J.L. Distinct mechanisms promote polarity establishment in carpels of Arabidopsis. Cell 1999, 99, 199-209. [CrossRef]

10. Yamaguchi, T.; Nagasawa, N.; Kawasaki, S.; Matsuoka, M.; Nagato, Y.; Hirano, H.Y. The YABBY gene DROOPING LEAF regulates carpel specification and midrib development in Oryza sativa. Plant Cell 2004, 16, 500-509. [CrossRef] [PubMed]

11. Liu, H.L.; Xu, Y.Y.; Xu, Z.H.; Chong, K. A rice YABBY gene, OsYABBY4, preferentially expresses in developing vascular tissue. Dev. Genes Evol. 2007, 217, 629-637. [CrossRef] [PubMed]

12. Ohmori, Y.; Abiko, M.; Horibata, A.; Hirano, H.Y. A transposon, Ping, is integrated into intron 4 of the DROOPING LEAF gene of rice, weakly reducing its expression and causing a mild drooping leaf phenotype. Plant Cell Physiol. 2008, 49, 1176-1184. [CrossRef] [PubMed]

13. Ohmori, Y.; Toriba, T.; Nakamura, H.; Ichikawa, H.; Hirano, H.Y. Temporal and spatial regulation of DROOPING LEAF gene expression that promotes midrib formation in rice. Plant J. 2011, 65, 77-86. [CrossRef] [PubMed]

14. Tanaka, W.; Toriba, T.; Ohmori, Y.; Yoshida, A.; Kawai, A.; Mayama-Tsuchida, T.; Ichikawa, H.; Mitsuda, N.; Ohme-Takagi, M.; Hirano, H.Y. The YABBY Gene TONGARI-BOUSHI1 Is Involved in Lateral Organ Development and Maintenance of Meristem Organization in the Rice Spikelet. Plant Cell 2012, $24,80-95$. [CrossRef] [PubMed]

15. Lee, J.Y.; Baum, S.F.; Oh, S.H.; Jiang, C.Z.; Chen, J.C.; Bowman, J.L. Recruitment of CRABS CLAW to promote nectary development within the eudicot clade. Development 2005, 132, 5021-5032. [CrossRef] [PubMed]

16. Morel, P.; Heijmans, K.; Ament, K.; Chopy, M.; Trehin, C.; Chambrier, P.; Rodrigues Bento, S.; Bimbo, A.; Vandenbussche, M. The Floral C-Lineage Genes Trigger Nectary Development in Petunia and Arabidopsis. Plant Cell 2018, 30, 2020-2037. [CrossRef] [PubMed]

17. Bowman, J.L.; Smyth, D.R. CRABS CLAW, a gene that regulates carpel and nectary development in Arabidopsis, encodes a novel protein with zinc finger and helix-loop-helix domains. Development 1999, 126, 2387-2396. [PubMed]

18. Brown, W.H. The bearing of nectaries on the phylogeny of flowering plants. Proc. Am. Phil. Soc. 1938, 79, 549-595.

19. Endress, P.K. The Flowers in Extant Basal Angiosperms and Inferences on Ancestral Flowers. Int. J. Plant Sci. 2001, 162, 1111-1140. [CrossRef]

20. Fahn, A. The topography of the nectary in the flower and its phylogenetic trend. Phytomorphology 1953, 3, 424-426.

21. Kozomara, B.; Vinterhalter, B.; Radojevic, L.; Vinterhalter, D. In vitro propagation of Chimonanthus praecox (L.), a winter flowering ornamental shrub. In Vitro Cell Dev. Biol. Plant 2008, 44, 142-147. [CrossRef] 
22. Xiang, L.; Zhao, K.; Chen, L. Molecular cloning and expression of Chimonanthus praecox farnesyl pyrophosphate synthase gene and its possible involvement in the biosynthesis of floral volatile sesquiterpenoids. Plant Physiol. Biochem. 2010, 48, 845-850. [CrossRef] [PubMed]

23. Zhao, K.G.; Zhou, M.Q.; Chen, L.Q.; Zhang, D.L.; Robert, G.W. Genetic diversity and discrimination of Chimonanthus praecox (L.) link germplasm using ISSR and RAPD markers. Hortscience 2007, 42, 1144-1148.

24. Vainstein, A.; Lewinsohn, E.; Pichersky, E.; Weiss, D. Floral Fragrance. New Inroads into an Old Commodity. Plant Physiol. 2001, 127, 1383-1389. [CrossRef] [PubMed]

25. Kram, B.W.; Carter, C.J. Arabidopsis thaliana as a model for functional nectary analysis. Sex. Plant Reprod. 2009, 22, 235-246. [CrossRef] [PubMed]

26. Ma, L.; Li, H.F.; Peng, C.C.; Chen, Z.Z.; Long, Z.F. Cloning of SAMT gene cDNA from Chimonanthus praecox and its expression in Escherichia coli. Agric. Sci. Technol. 2012, 13, 82-87.

27. Liu, D.; Sui, S.; Ma, J.; Li, Z.; Guo, Y.; Luo, D.; Yang, J.; Li, M. Transcriptomic analysis of flower development in wintersweet (Chimonanthus praecox). PLoS ONE 2014, 9, e86976. [CrossRef] [PubMed]

28. Xue, B.; Shao, Y.Y.; Saunders, R.M.; Tan, Y.H. Alphonsea glandulosa (Annonaceae), a New Species from Yunnan, China. PLoS ONE 2017, 12, e0170107. [CrossRef] [PubMed]

29. Nepi, M. Nectary structure and ultrastructure. In Nectaries and Nectar; Nicolson, S.W., Nepi, M., Pacini, E., Eds.; Springer: Dordrecht, The Netherlands, 2007; pp. 129-166.

30. Elias, T.S. Extrafloral nectaries: Their structure and distribution. In The Biology of Nectaries; Bentley, B., Elias, T.S., Eds.; Columbia University Press: New York, NY, USA, 1983; pp. 174-203.

31. Bremer, B.; Bremer, K.; Chase, M.W.; Fay, M.F.; Reveal, J.L.; Soltis, D.E.; Soltis, P.S.; Stevens, P.F.; Anderberg, A.A.; Moore, M.J.; et al. An update of the Angiosperm Phylogeny Group classification for the orders and families of flowering plants: APG III. Bot. J. Linn. Soc. 2009, 161, 105-121.

32. Deng, C.; Song, G.; Hu, Y. Rapid determination of volatile compounds emitted from Chimonanthus praecox flowers by HS-SPME-GC-MS. Z. Naturforsch. C 2004, 59, 636-640. [CrossRef] [PubMed]

33. Miller, E.R.; Taylor, G.W.; Eskew, M.H. The volatile oil of calycanthus floridus. J. Am. Chem. Soc. 1914, 36, 2182-2185. [CrossRef]

34. Azuma, H.T.M.; Asakawa, Y. Floral Scent Chemistry and Stamen Movement of Chimonanthus praecox (L.) Link (Calycanthaceae). Acta Phytotaxon. Geobot. 2005, 56, 197-201.

35. Juarez, M.T.; Twigg, R.W.; Timmermans, M.C. Specification of adaxial cell fate during maize leaf development. Development 2004, 131, 4533-4544. [CrossRef] [PubMed]

36. Thompson, J.D.; Gibson, T.J.; Plewniak, F.; Jeanmougin, F.; Higgins, D.G. The CLUSTAL_X windows interface: Flexible strategies for multiple sequence alignment aided by quality analysis tools. Nucleic Acids Res. 1997, 25, 4876-4882. [CrossRef] [PubMed]

37. Tamura, K.; Dudley, J.; Nei, M.; Kumar, S. MEGA4: Molecular Evolutionary Genetics Analysis (MEGA) software version 4.0. Mol. Biol. Evol. 2007, 24, 1596-1599. [CrossRef] [PubMed]

38. Yeung, K.Y.; Fraley, C.; Murua, A.; Raftery, A.E.; Ruzzo, W.L. Model-based clustering and data transformations for gene expression data. Bioinformatics 2001, 17, 977-987. [CrossRef] [PubMed]

(c) 2018 by the authors. Licensee MDPI, Basel, Switzerland. This article is an open access article distributed under the terms and conditions of the Creative Commons Attribution (CC BY) license (http://creativecommons.org/licenses/by/4.0/). 